\title{
Learned Helplessness and the Generality of Social Loafing
}

\author{
Christopher Peterson, ${ }^{1}$ Stephen J. Zaccaro, and Daniel C. Daly \\ Virginia Polytechnic Institute and State University
}

Theorists have suggested that social loafing is an instance of learned helplessness. We argue that this explanation is unwarranted in the absence of evidence that social loafing is generalized from one situation to another. We report an experiment consistent with our argument. College students working in a group performed more poorly at a word-generating task than subjects working by themselves, but this social loafing was not associated with subsequent problem-solving difficulties or with sad affect.

KEY WORDS: learned helplessness; social loafing.

As a result of experience with uncontrollable events, people may learn to expect subsequent outcomes to be independent of responses. When generalized, such an expectation is responsible for later deficits in learning, motivation, and emotion (Seligman, 1975). This learned helplessness phenomenon has been proposed as a model or mechanism for a variety of human ills involving maladaptive passivity: depression, burnout, academic failure, stagnation of the lower class, response to victimization, susceptibility to illness, and so on (Garber \& Seligman, 1980).

Such applications of learned helplessness have often been overly metaphorical. "Learned helplessness" may be invoked solely on the basis of observed passivity in a single situation (Peterson, 1982). This is unjustified,

'Address all correspondence to Christopher Peterson, Department of Psychology, University of Michigan, 580 Union Drive, Ann Arbor, Michigan 48109. 
of course, since passivity may have numerous determinants, including the mundane process of extinction. Only if deficits are mediated by a belief in response-outcome independence is learned helplessness arguably present (Peterson, 1985). One way to see if expectations of helplessness are involved is to investigate whether deficits induced in one situation generalize to another (Seligman, Maier, \& Peterson, in preparation).

We believe learned helplessness to be a useful explanation for some failures of human adaptation. We also believe that careless application of the model obscures its value. In the present article, we illustrate how the researcher might critically examine a particular phenomenon for the possible involvement of learned helplessness. We chose to study social loafing since some theorists have interpreted it in learned helplessness terms.

Social loafing is the decrease in individual effort and performance sometimes observed when people work in groups as opposed to by themselves (Latané, Williams, \& Harkins, 1979). Social loafing has been demonstrated for a variety of behaviors, including such physical actions as clapping and yelling (Latané et al., 1979; Williams, Harkings, \& Latané, 1981), rope pulling (Ingham, Lewinger, Graves, \& Peckham, 1974), bulb pumping (Kerr \& Bruun, 1981), and paper folding (Zaccaro, 1984), as well as such cognitive actions as eassy evaluation (Petty, Harkins, Williams, \& Latané, 1977) and brainstorming (Harkins \& Petty, 1982).

"Social loafing" has been used in several senses. Some theorists apply the term to any motivation loss that occurs in a group setting, while others reserve social loafing for a motivation loss at an additive task that occurs as a group size increases and individual identifiability decreases (Kerr \& Bruun, 1983). In the present article, we follow this second, more restricted, use of social loafing.

Why does social loafing occur? Latané et al. (1979) suggested three possible mediators. First, group members may attribute lower effort and motivation to fellow participants and respond by lowering their own effort accordingly. Second, group members may set individual goals that vary with group size. So, as groups increase in size, individuals may set lower goals for themselves and thereby perform at lower levels. The third explanation suggested by Latané et al. (1979) is that social loafing results from learned helplessness: the obscuring of the contingency between (individual) responses and (group) rewards when individual responses cannot be identified (Williams et al., 1981).

If social loafing plausibly explained by learned helplessness? Perhaps, since it is a motivational deficit occurring when response-outcome contingencies are removed. But no data show that social loafing is accompanied by an expectation of response-outcome independence, one that generalizes to a second task in which contingencies are in place. One test of whether 
learned helplessness accounts for social loafing is to investigate the generality of social loafing from one task to another.

Accordingly, subjects participated in a brainstorming task (generating uses for a common object) either in a group or by themselves. A social loafing effect was expected: Subjects working in a group should generate fewer uses than subjects working by themselves. Subjects were then tested individually on an anagram solution task similar to those used in learned helplessness experiments to index cognitive/motivational deficits (e.g., Hiroto $\&$ Seligman, 1975). Since learned helplessness is sometimes accompanied by sad affect, subjects completed a mood questionnaire as a supplemental measure of learned helplessness (Peterson \& Seligman, 1984). In a third condition, subjects completed just the anagram task and the mood questionnaire, without a prior brainstorming task.

If social loafing involves learned helplessness, as Latané et al. (1979) suggested, then subjects who worked at the brainstorming task in a group should solve fewer anagrams and report sadder affect than subjects in the individual brainstorming condition or the no-brainstorming condition. We suspect that these effects will not occur, however, and we will then conclude that learned helplessness is not a good explanation of social loafing.

\section{METHOD}

\section{Subjects}

The research participants were 64 students enrolled in Introductory Psychology at Virginia Tech who received extra credit toward their final course grade. Subjects were assigned to one of three conditions: individual brainstorming ( $n=21)$, group brainstorming $(n=20)$, and no brainstorming $(n=23)$. Approximately equal numbers of men and women were represented in each condition. Sex of subject did not affect the results and will not be discussed further.

\section{Materials and Procedure}

Subjects in a given condition participated in a single session at the same time in the same room. Each was seated at some distance from others and was given a booklet that contained written instructions and experimental materials. Subjects did not put their name anywhere on this material. The experimenter repeated the instructions out loud while the subjects read to 
themselves. The brainstorming task was adapted from Harkins and Petty (1982).

Subjects in the individual brainstorming condition were given the following instructions:

Today you will take part in what is known as a brainstorming task. You will be given the name of an object, and your task will be to think of as many uses for this object as you can. Don't be concerned with the quality of your reactions. The uses can be ordinary or unusual. Simply list as many as you can.

Before the actual task, let us spend a few minutes with a practice task. Turn the page when you are told to do so, and list as many uses as you can for the object named at the top of the page. Do not go on until you are told to do so.

A practice task was included because pilot work suggested that some subjects had difficulty understanding the task instructions. For the practice task, the word was light bulb. Subjects listed uses for 5 minutes, when the experimenter asked them to stop. For the actual task, the word was knife, and subjects listed uses for 8 minutes.

Subjects then completed a written anagrams task. At the top of the page were 30 five-letter anagrams. Subjects were given 5 minutes to unscramble as many as they could, writing solutions at the bottom of the page. Finally, subjects completed the Multiple Affect Adjective Check List (MAACL; Zuckerman \& Lubin, 1965), which provides a measure of depressed mood. Booklets were turned in at the end of the experiment by dropping them into a box.

Subjects in the group brainstorming condition were treated identically, except that they were provided these additional instructions for the brainstorming task:

Everyone in this room is a member of a group that will be listing uses for the same object. The goal for the group is to come up with as many different uses for this object as possible. Thus, you share the responsibility for listing uses with the other people in your group.

It was emphasized to subjects that only a group score would be calculated and that individual responses were of concern only to the degree that they contributed to the group score. However, before these subjects began the anagrams, they were told that it was an individual task and that their particular score was of concern.

Finally, subjects in the no-brainstorming condition completed just the anagram task and the MAACL.

\section{RESULTS}

For subjects in the individual and group brainstorming conditions, the number of different uses generated by subjects was calculated for the prac- 
tice task (light bulb) and for the actual task (knife). As our pilot work suggested, a statistically reliable loafing effect was not obtained with the practice task (5.14 uses vs. 4.48 uses, in the individual vs. group conditions, $t=.84$, n.s.), but a highly reliable social loafing effect was obtained with the actual task (see Table I).

In order to rule out the possibility that the different numbers of uses for the two conditions resulted from subjects in the group brainstorming conditioning generating more unusual and therefore fewer uses (Harkins \& Petty, 1982), two judges blindly and independently rated all the uses generated by subjects on a 3-point scale of unusualness. Ratings by the two judges were highly correlated, $r=.87$. These were combined and averaged across the uses generated by a given subject. As Table I shows, subjects in the two brainstorming conditions u1d not differ in how unusual their uses were.

For subjects in all three conditions, the anagrams correctly solved were calculated, as were scores on the depression subscale of the MAACL. The internal consistency of the depression subscale, as estimated by Cronbach's (1951) alpha, was .93. Table II shows the number of anagrams solved and the level of depression in each group. No significant differences were apparent among the groups for either measure. Hence, social loafing was not associated with generalized cognitive/motivational and emotional deficits.

\section{DISCUSSION}

Although a reliable social loafing effect resulted from the individual versus group brainstorming condition, this effect was not accompanied by deficits on subsequent measures similar to those produced by learned helplessness. So, we conclude that social loafing ought not to be viewed as an instance of learned helplessness, despite suggestions to this effect (Latané et al., 1979; Williams et al., 1981). Social loafing may result from the obscuring of response-outcome contingency at the social loafing task (Williams et al., 1981), but this need not imply learned helplessness. The present study shows that when response-outcome contingencies are reestablished on subse-

Table I. Performance at Brainstorming Task

\begin{tabular}{lccc}
\hline \multicolumn{1}{c}{ Measures } & $\begin{array}{c}\text { Individual } \\
\text { condition } \\
(n=21)\end{array}$ & $\begin{array}{c}\text { Group } \\
\text { condition } \\
(n=20)\end{array}$ & $t(39)$ \\
\hline Number of uses & 12.43 & 8.52 & $6.66^{a}$ \\
Average unusualness & 1.38 & 1.38 & \\
\hline${ }^{a} p<.0001$. & & &
\end{tabular}


Table II. Test Tasks Following Brainstorming

\begin{tabular}{lcccc}
\hline \multicolumn{1}{c}{ Individual } \\
Measure & $\begin{array}{c}\text { Group } \\
\text { condition } \\
(n=21)\end{array}$ & $\begin{array}{c}\text { No- } \\
(n=20)\end{array}$ & $\begin{array}{c}\text { condition } \\
\text { condition } \\
(n=23)\end{array}$ & $F(2,61)$ \\
\hline Number of anagrams & & & & .67 \\
$\quad$ solved & 5.96 & 7.29 & 7.52 & .67 \\
Depressed mood & 13.52 & 16.43 & 17.52 & 1.36 \\
\hline
\end{tabular}

quent individual tasks, effort decrements disappear. In contrast, learned helplessness involves the learning of response-outcome independence at one task and the transfer of this learning to a different task, resulting in general impairments (Seligman, 1975; Seligman et al., in preparation).

Several qualifications of our strong conclusion are in order. First, learned helplessness may be involved in some forms of group motivation loss, to the broader use of the social loafing concept (cf. Kerr \& Bruun, 1983). Our results speak most directly to additive tasks in which individual identifiability is low. Second, we suspect that social loafing of the type we studied might have involved learned helplessness had several group tasks been employed. Prolonged and varied experience with obscured contingencies might produce helplessness at a later individual task. Third, we did not assess causal attributions by subjects for their group performance. The attributional reformulation of helplessness theory proposes that attributions affect the generalization of helplessness deficits (Peterson \& Seligman, 1984). To the degree that a group task suggests internal, stable, and global attributions, social loafing effects should generalize.

Nevertheless, the present results show that learned helplessness is not involved in social loafing in an obvious way. If nothing else, the burden of proof should be shifted to theorists who wish to use learned helplessness to explain social loafing. The simple observation of passivity is insufficient to conlude that learned helplessness is present.

The contribution of the present paper is more than a statement about what social loafing is not. We hope that we have shown how learned helplessness may be incorrectly applied to phenomena that resemble it only in terms of passivity. Further, we hope that we have shown that a more critical approach to the use of the helplessness model is possible. Researchers should similarly examine any phenomenon that they wish to explain with learned helplessness. Only through such scrutiny can learned helplessness escape the controversies that plague it (Peterson, 1985). 


\section{REFERENCES}

Cronbach, L. J. (1951). Coefficient alpha and the internal structure of tests. Psychometrika, 16, $297-334$.

Garber, J., \& Seligman, M. E. P. (Eds.). (1980). Human helplessness. New York: Academic Press.

Harkins, S., \& Petty, R. E. (1982). The effects of task difficulty and task uniquesness on social loafing. Journal of Personality and Social Psychology, 43, 1214-1229.

Hiroto, D. S., \& Seligman, M. E. P. (1975). Generality of learned helplessness in man. Journal of Personality and Social Psychology, 31, 311-327.

Ingham, A. G., Lewinger, G., Graves, J., \& Peckham, V. (1974). The Ringelman effect: Studies of group size and group performance. Journal of Experimental Social Psychology, 10, 371-384.

Kerr, N. L., \& Bruun, S. E. (1981). Ringelman revisited: Alternative explanations for the social loafing effect. Personality and Social Psychology Bulletin, 7, 224-231.

Kerr, N. L., \& Bruun, S. E. (1983). Dispensability of member effort and group motivation losses: Free-rider effects. Journal of Personality and Social Psychology, 44, 78-94.

Latané, B., Williams, K., \& Harkins, S. (1979). Many hands make light the work: The causes and consequences of social loafing. Journal of Personality and Social Psychology, 37, 822-832.

Peterson, C. (1982). Learned helplessness and health psychology. Health Psychology, 1, 153-168.

Peterson, C. (1985). Learned helplessness: Fundamental issues in theory and research. Journal of Social and Clinical Psychology, 3, 248-254.

Peterson, C., \& Seligman, M. E. P. (1984). Causal explantions as a risk factor for depression: Theory and evidence. Psychological Review, 91, 347-374.

Petty, R. E., Harkins, S., Williams, K., \& Latané, B. (1977). The effects of group size on cognitive effort and evaluation. Personality and Social Psychology Bulletin, 3, 579-582.

Seligman, M. E. P. (1975). Helplessness: On depression, development, and death. San Francisco: Freeman.

Seligman, M. E. P., Maier, S. F., \& Peterson, C. (in preparation). Learned helplessness. New York: Oxford.

Williams, K., Harkins, S., \& Latané, B. (1981). Identifiability as deterrent to social loafing: Two cheering experiments. Journal of Personality and Social Psychology, 40, 303-311.

Zaccaro, S. J. (1984). Social loafing: The role of task attractiveness. Personality and Social Psychology Bulletin, 10, 99-106.

Zuckerman, M., \& Lubin, B. (1965). Manual for the Multiple Affect Adjective Check List. San Diego: Educational and Testing Service. 